\title{
Coital blood pressure in hypertensives Cephalgia, syncope, and the effects of beta-blockade
}

\author{
STEWART MANN, MICHAEL W MILLAR CRAIG, BRIAN A GOULD, \\ DONALD I MELVILLE, E B RAFTERY
}

From the Department of Cardiology and the Division of Clinical Sciences, Northwick Park Hospital and Clinical Research Centre, Harrow, Middlesex

SUMMARY During the continuous monitoring of intra-arterial blood pressure in ambulant hypertensive subjects, 18 episodes of coitus were recorded in 11 subjects. Peak values of up to$300 / 175 \mathrm{mmHg}$ were found, the mean for men being $237 / 138 \mathrm{mmHg}$ and for women $216 / 127 \mathrm{~mm} \stackrel{\infty}{\oplus}$ $\mathrm{Hg}$. Two patients with coital symptoms (cephalgia and syncope) showed no unusual responses and,을 when restudied after beta-blockade, one subject showed no reduction in peak coital blood pressure. $\vec{c}$ The results complement those found previously in normal subjects and demonstrate the potential of the technique in investigating coital symptoms.

Sexual intercourse is occasionally associated with worrying symptoms or serious and even fatal complications. Attempts to define physiological changes therefore seem highly desirable, and have indeed been made by Masters and Johnson ${ }^{1}$ among others. The recording of physiological variables during coitus under laboratory conditions, however, creates an unnatural setting which may produce distorted results.

In the investigation of patients with hypertension, we have performed a large number of ambulatory recordings of intra-arterial pressure. Subjects were encouraged to behave as normally as possible, being little encumbered by the monitoring apparatus, and several had sexual intercourse during the recording period. We report here the heart rate and blood pressure changes during coitus in these subjects and also in two subjects monitored specifically to investigate symptoms related to coitus. Results from a subject who had coitus during an inital study and also during a restudy after treatment with a beta-adrenoceptor blocking agent are also reported.

\section{Methods}

Subjects with suspected or established hypertension who had been referred to the hypertension clinic at the hospital were asked to volunteer for a period of ambulatory intra-arterial blood pressure monitoring. They were asked to behave normally but encouragement to have coitus was not specifically given except to two subjects who complained of symptoms related to coitus. The experimental procedure for these ॠPresent address: Bristol Royal Infirmary, Bristol BS2 8HW. Accepted for publication 26 June 1981 studies was approved by the Hospital Ethical Com- $\frac{\vec{\oplus}}{\stackrel{\infty}{N}}$
mittee.

The monitoring equipment consisted of a revised version ${ }^{2}$ of a system initially developed in Oxford. ${ }^{3} \mathrm{~A}$ cannula was inserted percutaneously under localō anaesthesia into the non-dominant brachial artery of the subject and joined by fine-bore tubing to $a \stackrel{D}{2}$ transducer/perfusion device. Signals from this and from adhesive chest electrocardiographic electrodes 3 were recorded on two channels of cassette tape using aminiature recorder ("Medilog", Oxford Medical Sys-0. tems). Enough wire was provided to allow the subject to position the recorder either behind him or at his side when lying flat. No event-marking system was? used during these recordings but the time of occur-3 rence of intercourse was recorded in the subject'sin. diary. The system was calibrated each morning and evening during the recording.

In accordance with our standard procedure all tapes were written out in full using a pen-recorder (Lec $\frac{}{2}$ tromed). Episodes of sexual activity were easily iden tified and later replayed at faster paper speed using क fibreoptic recorder (Medelec Ltd). The nearest calib ration signals were written out using the same systemo on an identical setting. The mean blood pressure an $\delta^{\infty}$ heart rate during the one minute before fluctuations associated with sexual activity were taken as precoitaf recordings and the highest levels sustained for five of more beats as "peak coital" values.

\section{Results}

Technically satisfactory recordings of coital bloo 
pressure were made on 18 occasions involving 11 hypertensive subjects, representing $1.5 \%$ of all studies performed during this period. The mean age of the subjects was 42 years (range 29-56 years). The group included three women. The details of the patients and their recorded heart rates and blood pressures are shown in Tables 1 and 2.

The recordings showed that both heart rate and blood pressure fluctuated widely during sexual activity occasionally reaching very high levels. Though patterns varied greatly the highest peak of heart rate and blood pressure (presumably associated with orgasm) were generally simultaneous and were followed by a rapid fall to precoital levels or below. Examples of recordings can be seen in Fig. 1 (men) and Fig. 2 (women). All men achieved orgasm but only one of the women was known to have done so (case 10). Case 5 did not achieve orgasm and details for case 1 were insufficient.

Peak blood pressures were very high, the mean being $237 / 133 \mathrm{mmHg}$ (range 184 to $300 / 92$ to 175 $\mathrm{mmHg}$ ) for men and $216 / 127 \mathrm{mmHg}$ (range 190 to $260 / 110$ to $155 \mathrm{mmHg}$ ) for women (Table 1 and 2). These levels were sustained in each case for only a few seconds. Peak heart rates were 131 beats/minute and 96 beats/minute for men and women, respectively.

\section{Case reports}

CASE 2

A 42-year-old Australian was referred because of "blinding" global headaches lasting between 10 minutes and one hour, precipitated only by sexual intercourse with extramarital partners. Examination was normal except that his blood pressure was moderately raised $(165 / 115 \mathrm{mmHg})$. Routine investigations including urinary catecholamine excretion were normal.

An ambulatory blood pressure recording lasting 36 hours was undertaken during which he achieved orgasm five times. As can be seen from Table 1, the highest pressure experience $(243 / 151 \mathrm{mmHg}$ ) was during intercourse with his wife. No headaches occurred during the recording and maximum pressures were within the range shown by asymptomatic hypertensives. Antihypertensive medication was prescribed (propranolol $80 \mathrm{mg}$ bid and cyclopenthiazide $0.25 \mathrm{mg}$ daily) and despite no loss of sexual function, headaches did not recur. He remains well, normotensive, and free from headaches, three years after the study.

\section{CASE 5}

This housewife of 39 years was referred for investigation of syncopal attacks. Borderline hypertension was noted (130 to $150 / 95$ to $110 \mathrm{mmHg}$ ) and screening investigations including electrocardiogram and electroencephalogram were all normal. Attacks of dizziness increased in frequency, some coming on without warning and leading to unconsciousness and generally lasted for about three minutes. Her husband reported no signs of epileptic convulsions and empirical treatment with propranolol, digoxin, procainamide, or phenytoin did not affect the attacks, the only consistent trigger of which was sexual intercourse.

Outpatient electrocardiographic monitoring spanned a typical attack but no arrhythmia was detected. A period of 48 hours of ambulatory blood pressure monitoring was carried out during which a typical attack with loss of consciousness followed sexual intercourse (no orgasm); the record is shown in Fig. $2 \mathrm{~b}$. No arrhythmia or period of sustained or pronounced hypotension was apparent.

The patient was strongly reassured and treatment (cyclopenthiazide $0.5 \mathrm{mg}$ daily) given for the hypertension. Over the subsequent two years the attacks decreased in frequency and their description seems to indicate a non-organic nature.

\section{CASE 7}

This 29-year-old agricultural research worker had sexual intercourse twice during a routine ambulatory blood pressure assessment after borderline clinic readings. He was later treated for hypertension (sotalol 80 $\mathrm{mg}$ tid) and on a subsequent recording he had sexual intercourse again. All three episodes occurred in the early afternoon and the subject felt them to be comparable. Peak coital values of heart rate and blood pressure achieved during the restudy were between those found during the two pretreatment episodes, despite both clinic and mean ambulatory measurements indicating sacisfactory blood pressure reduction (see Table 1).

\section{Discussiun}

Sexual intercourse probably affects the cardiovascular system by a number of component methods. There are certainly elements of both isometric and dynamic exercise, breath-holding episodes, and psychological stress, all of which are known to increase heart rate and blood pressure. In addition there is the general activity of autonomic reflexes necessarily involved in arousal, erection, orgasm, and ejaculation. That sexual arousal, as opposed to other strong emotions, produced consistent rises in heart rate and blood pressure in young men was shown by Scott in $1930 .^{4}$ Later workers ${ }^{156}$ have shown the extreme magnitude of these changes in some subjects when monitoring covered the period of orgasm. All these studies, however, were carried out under laboratory conditions and subject to the potential sources of bias 
(a)

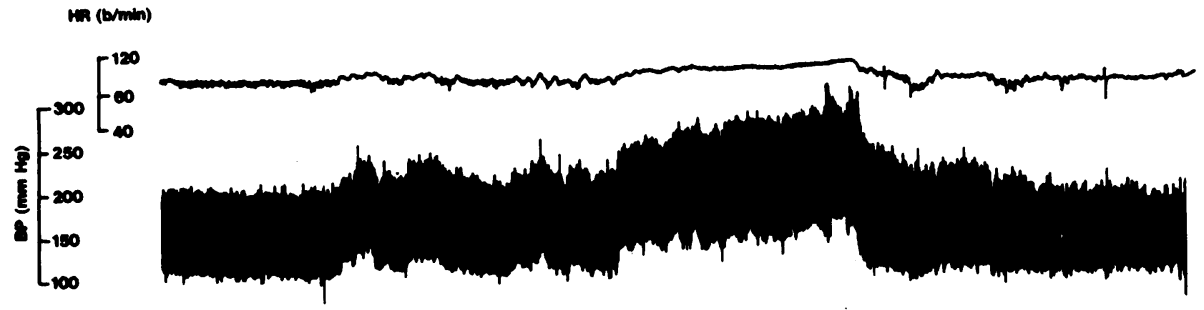

(b)

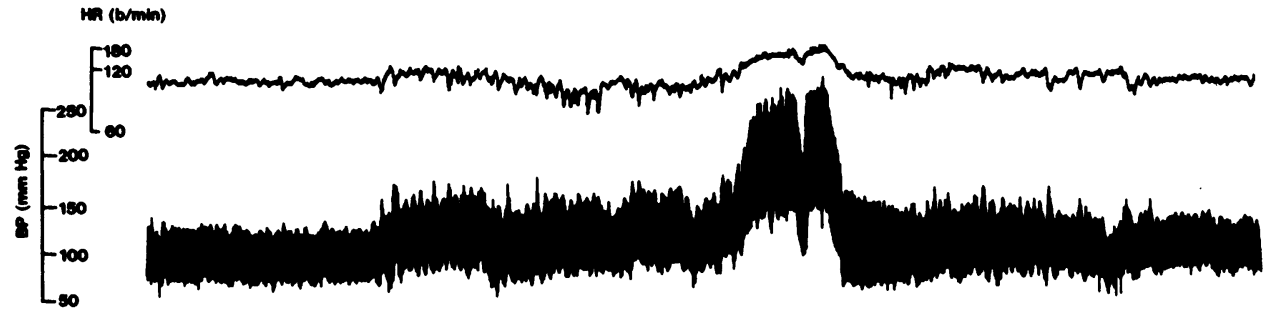
2030

(c)

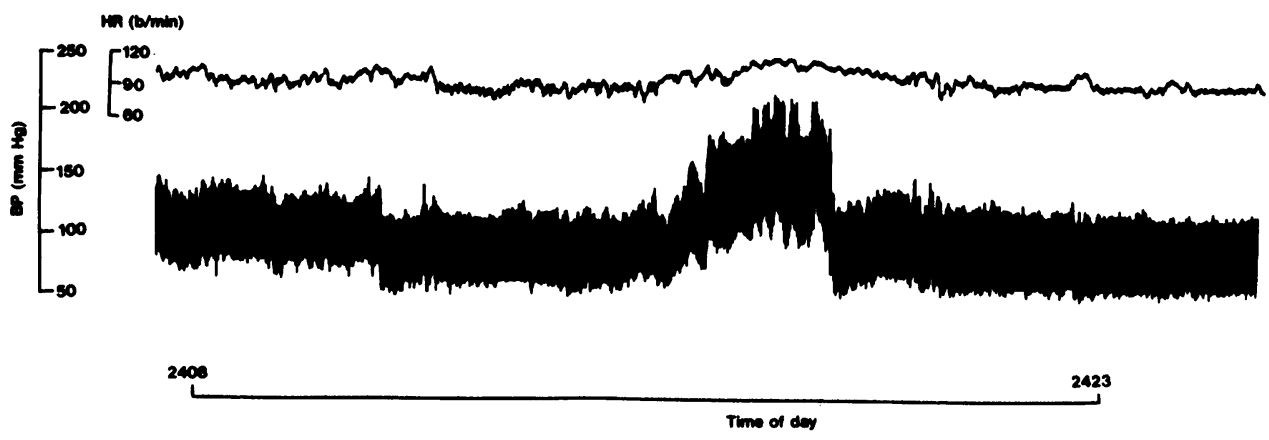

Fig. 1 Examples of coital blood pressure recordings in three hypertensive men: (a) case 2; (b) case 6; (c) case 8. Note the widely fluctuating pattern and simultaneous peaks in heart rate and blood pressure at the time of presumed orgasm.

mentioned earlier. When Hellerstein and Friedman ${ }^{7}$ monitored the ambulant electrocardiograms of middle-aged patients with ischaemic heart disease they found that the peak coital heart rates were much lower than those expected from laboratory results.

The rapid changes in heart rate and blood pressure also indicate the need for a measuring system using continuous monitoring; the value of intermittent noninvasive measurements is clearly questionable. Littler et al. ${ }^{8}$ using monitoring equipment similar to ours, reported heart rate and blood pressure in six men and $C$ one woman (all normotensive), and showed that intra- $\mathbb{\infty}$ arterial pressures of up to $233 / 128 \mathrm{mmHg}$ were + achieved during coitus. From our study it is apparent $\frac{7}{2}$ that those subjects starting with higher baseline levels $\underset{\mathrm{D}}{\mathrm{O}}$ reached correspondingly higher peak pressures dur- $\frac{\mathrm{O}}{\mathrm{D}}$ ing coitus.

It is possible that pathological cardiovascular events 
(a)

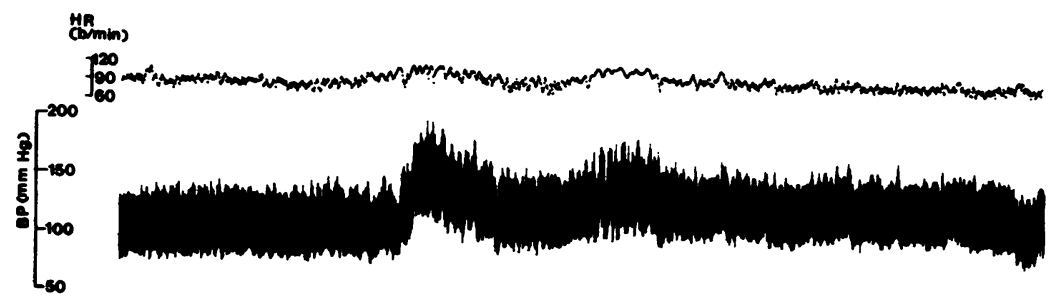

1495

(b)

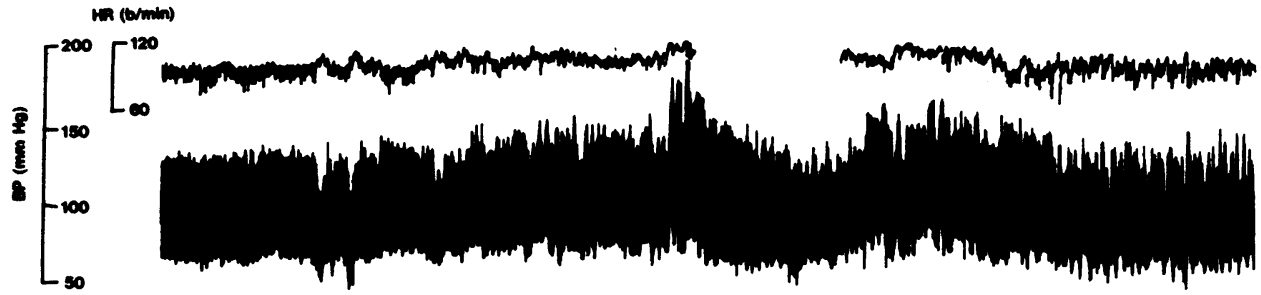

2315

2325

(c)

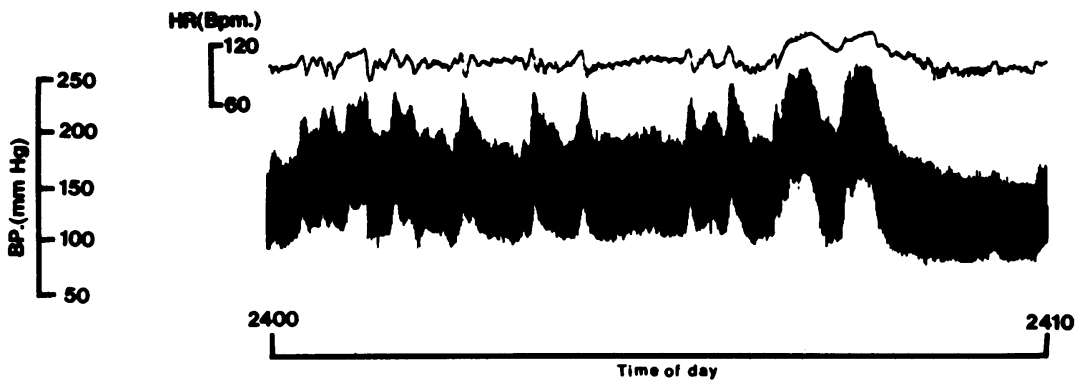

Fig. 2 Examples of coital blood pressure recordings in three hypertensive women: (a) case 1 (orgasm not recorded); (b) case 5 (no orgasm, coital syncope); (c) case 10 (orgasm).

occur directly as a result of high peak pressures in hypertension (or ischaemic heart disease) and, if so, the implications for management, both in terms of behaviour modification and antihypertensive medication, are profound. Such events known to be associated with sexual activity include angina pectoris, myocardial infarction, sudden cardiac death, cerebral haemorrhage, and other neurological symptoms. Though anecdotal evidence for the occurrence of the more serious complications is common, epidemiological surveys ${ }^{9-11}$ suggest that this is not the case. Recurrent and worrying symptoms are also uncommon but may, as exemplified by cases 2 and 5, present problems of diagnosis.

Coital cephalgia, noted by Hippocrates ${ }^{12}$ and documented more fully in recent years, may occasionally be a manifestation of subarachnoid haemorrhage ${ }^{13} \quad 14$ but more usually appears to follow a benign 
Table 1 Details of patients and coital blood pressure levels in eight hypertensive men. Comparative mean values from the study by Littler et al. ${ }^{8}$ have been included

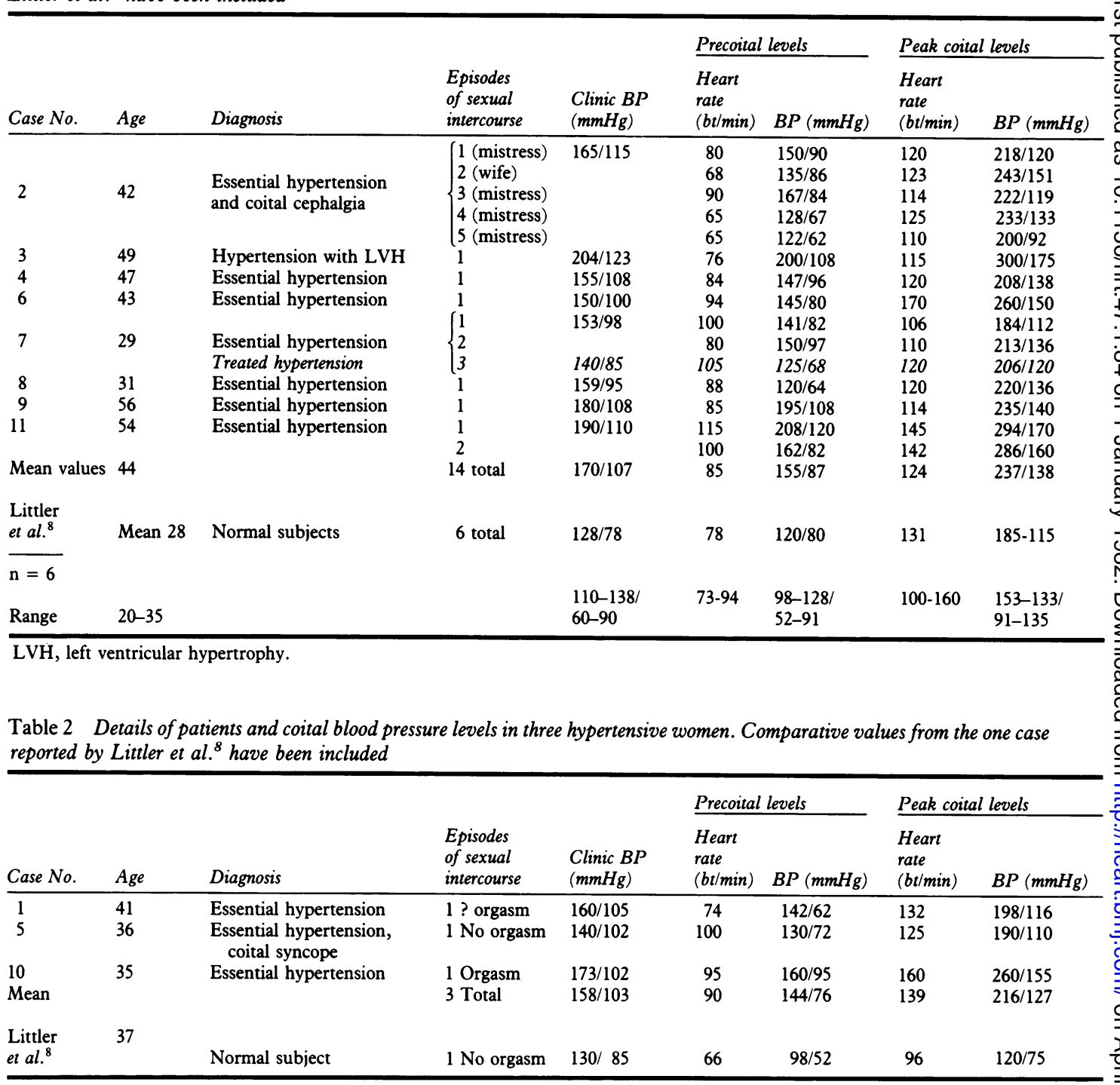

course. ${ }^{15-17}$ Though symptoms may be severe, such that invasive investigations have been performed, diagnoses of the underlying mechanism have remained speculative and treatment empirical. Lance $^{17}$ in his series describes raised resting blood pressure in seven of his 21 patients, in common with case 2.

Coital syncope was described in several of the patients reported by $\mathrm{Kriz},{ }^{13}$ and tentative explanations have included hyperventilation, cardiac arrhythmia, hypotension, and cerebrovascular insufficiency caused by cervical spondylosis. In our patient the symptoms were clearly not those of le petit mort, $N$ occasionally described in association with profound $\underset{\mathrm{E}}{ }$ orgasm, as some episodes were not associated with 0 sexual activity. The normal results of investigations, lack of objective observers, and subsequent descrip- $\frac{C}{D}$ tion of attacks, however, have led us to entertain a $\stackrel{\oplus}{+}$ functional rather than organic diagnosis. In spite of 7 the negative results in both these patients, ambulatory $\overrightarrow{0}$ blood pressure monitoring did help to exclude some $\stackrel{\odot}{\odot}$ diagnoses and we feel its use should be considered in $\underset{\mathbb{Q}}{\mathbb{Q}}$ other similar cases.

The treatment of symptoms (and the prophylaxis 
against pathological events) associated with coitus could comprise any of a range of measures from complete abstinence to behaviour modification ${ }^{18}$ and drug treatment. Jackson ${ }^{19}$ reported that appropriate management in timing and conditions of coitus together with appropriate drug treatment could reduce considerably the incidence of anginal attacks, while Fox ${ }^{20}$ showed that in one pair of (normotensive) subjects, propranolol reduced peak coital systolic pressure. Again in this respect (case 7), variability in response possibly defeated any attempt to show a definite trend (or lack of it) after beta-blockade. It may be that if isometric exercise is a prominent component of coitus the antihypertensive effect of beta-blockers and many other drugs may be limited, ${ }^{21}$ though recent work in rabbits has shown reduction of peak coital heart rate, blood pressure, and plasma noradrenaline concentration after propranolol. ${ }^{22}$

The acquisition of further comparable information is clearly desirable, though the ethical objections to collecting data with invasive techniques are considerable and the reliability of non-invasive techniques of measuring blood pressure, especially during physical activity, is questionable. The elucidation of some recurrent symptomatic problems or evidence of their benign nature, however, may usefully be gained by this method.

We wish to thank Mr S Dashwood for technical help, and Drs P Taggart and A A Buchanan for permission to report cases under their care.

1 Masters WH, Johnson VE. Human sexual response. Boston: Little Brown, 1966.

2 Millar Craig MW, Hawes DWC, Whittington JR. New system for recording ambulatory blood pressure in man. Med Biol Eng Comput 1978; 16: 727-31.

3 Bevan A, Honour AJ Stott FG. Portable recorder for continuous arterial pressure measurement in man. $\mathcal{F}$ Physiol (Lond) 1966; 186: 3p.

4 Scott JC. Systolic blood-pressure fluctuations with sex, anger and fear. F Comp Psychol 1930; 10: 97-114.

5 Klumbies $G$, Kleinsorge $H$. Circulatory dangers and prophylaxis during orgasm. International foumal of Sexology $1950 ; 4$ : 61-6.
6 Bartlett RG, Bohr VC. Physiological responses during coitus in the human (abstract). Fed Proc 1956; 15, 10.

7 Hellerstein HK, Friedman EH. Sexual activity and the postcoronary patient. Arch Intern Med. 1970; 125: 987-99.

8 Littler WA, Honour AJ, Sleight P. Direct arterial pressure, heart rate and electrocardiogram during human coitus. F Reprod Fertil 1974; 40: 321-31.

9 Myers A, Dewar HA. Circumstances attending 100 sudden deaths from coronary artery disease with coroner's necropsies. Br Heart $\mathcal{F}$ 1975; 37: 1133-43

10 Tunstall Pedoe H, Clayton D, Morris JN, Brigden W, McDonald L. Coronary heart-attacks in East London. Lancet 1975; ii: 833-3.

11 Ueno M. On the so-called coition death. Nihon University Fournal of Medicine 1965; 7: 235-42.

12 Adams F. The genuine works of Hippocrates. London: Sydenham Society, 1849: 94.

$13 \mathrm{Kriz} \mathrm{K}$. Coitus as a factor in the pathogenesis of neurological complications. (Czech) Cesk Neurol 1970; 33: 162-7.

14 Lundberg PO, Osterman PO. The benign and malignant forms of orgasmic cephalgia. Headache 1974; 14: 164-5.

15 Paulson GW, Klawans HL Jr. Benign orgasmic cephalgia. Headache 1974; 13: 181-7.

16 Martin EA. Headache during sexual intercourse (coital cephalgia): a report on six cases. Ir $\mathcal{F}$ Med Sci 1974; 143: 342-5.

17 Lance JW. Headaches related to sexual activity. $\mathcal{F}$ Neurol Neurosurg Psychiatry 1976; 39: 1226-30.

18 Nemec ED, Mansfield L, Kennedy JW. Heart rate and blood pressure responses during sexual activity in normal males. Am Heart $\mathcal{F}$ 1976; 92: 274-7.

19 Jackson G. Sexual intercourse and angina pectoris. $\mathrm{Br}$ Med F 1978; ii: 16.

20 Fox CA. Reduction in the rise of systolic blood pressure during human coitus by the beta-adrenergic blocking agent, propanolol. $\mathcal{F}$ Reprod Fertil 1970; 22: 587-90.

21 Watt SJ, Thomas RD, Belfield PW, Goldstraw PW, Taylor SH. Influence of sympatholytic drugs on the cardiovascular response to isometric exercise. Clin Sci 1981; 60: 139-43.

22 Gordon D, Roddis SA, Sever PS. Effect of propranolol on heart rate, blood pressure and plasma noradrenaline during coitus in the rabbit. Clin Sci 1980; 59: 231-6.

Requests for reprints to Dr E B Raftery, Northwick Park Hospital, Watford Road, Harrow, Middlesex HAl 3UJ. 